SISTEMA
ELETRONICO
DE REVISTAS
SER I UFPR

\title{
Conhecimento tradicional e o impacto da salinização em comunidades agrícolas no norte do Estado do Rio de Janeiro, Brasil
}

\section{Traditional knowledge and impact of salinization in agricultural communities from north of Rio de Janeiro State, Brazil}

\author{
Raquel da Silva PAES ${ }^{1 *}$, Sérgio Carvalho MOREIRA², Camilah Antunes ZAPPES ${ }^{1}$ \\ ${ }^{1}$ Programa de Pós Graduação em Geografia, Universidade Federal Fluminense (UFF), Campos dos Goytacazes, RJ, Brasil. \\ 2 Departamento de Vertebrados, Museu Nacional, Universidade Federal do Rio de Janeiro (UFRJ), Rio de Janeiro, RJ, Brasil. \\ *E-mail de contato: raquelspaes@hotmail.com
}

Artigo recebido em 2 de agosto de 2017, versão final aceita em 24 de agosto de 2018.

RESUMO: $\quad$ O presente estudo aborda o conhecimento tradicional de agricultores familiares sobre a salinização dos corpos hídricos e do solo no $5^{\circ}$ Distrito do município de São João da Barra, Estado do Rio de Janeiro, e viabilidade da agricultura frente à instalação do Complexo Logístico Industrial do Porto do Açu (CLIPA). Por meio da etnografia foram realizadas 50 entrevistas etnográficas junto aos agricultores locais. As interferências sobre a agricultura familiar descritas envolvem principalmente a salinização dos corpos hídricos e solo causada pela instalação do CLIPA e questões financeiras decorrentes da perda da lavoura. A continuidade da atividade na região pode estar comprometida devido à intensificação da salinização após a instalação do megaempreendimento. Políticas públicas devem ser planejadas em conjunto com as comunidades locais, o poder público, as instituições privadas responsáveis pelo CLIPA, e as instituições de pesquisa da região a fim de manter as práticas sócio-culturais e economia locais.

Palavras-chave: agricultura tradicional; impactos de empreendimentos portuários; salinização.

ABSTRACT: This present work regards to the traditional knowledge of the family farmers in connection with the salinization of both the water bodies and the soil in the Açu district, municipality of São João da Barra, in the state of Rio de Janeiro - Brazil and the feasibility of the agriculture in the face of the installation of the Industrial Logistical Complex of the Açu Port - CLIPA. By means of ethnography, fifty interviews were carried out 
with local farmers. The interferences on the family farming described by the interviewed farmers are mainly related to the salinization of the water bodies and soil caused by the installation of CLIPA and also to the financial matters arising out of the loss of the crops. The continuity of the activity in the region may be compromised because of the growing intensity of the salinization after the installation of the aforementioned enterprise. Public policies should be planned with the participation of the local communities, the government, the private institutions responsible for the CLIPA and the research institutions of the region, in order to maintain the social, cultural and economic practices carried out in such district.

Keywords: traditional agriculture; impacts of port projects; salinization.

\section{Introdução}

Desde o desenvolvimento inicial da agricultura o ser humano sempre demonstrou dependência em relação aos corpos hídricos, ao solo e suas propriedades devido ao cultivo e coleta de recursos para a alimentação, produtos medicinais e matérias-primas para atividades de caça e vestimenta (Resende et al., 1995). Comunidades agrícolas utilizam estes recursos baseado principalmente no conhecimento tradicional desenvolvido por meio de experiências empíricas das relações sociedade-natureza (Pereira \& Diegues, 2010), o que torna a percepção da realidade distinta do conhecimento considerado não tradicional (Agrawal, 1995; Diegues, 2000).

Tais comunidades apresentam o conhecimento tradicional adquirido ao longo de gerações, sendo este repassado oralmente entre seus membros (Diegues, 2000). Desta maneira, torna-se fundamental valorizar este conhecimento com suas práticas ancestrais já que sua utilização permite o desenvolvimento do manejo tradicional adequado à conservação dos ecossistemas (Queiroz, 2005).

Atualmente, diversas áreas no Brasil sofrem interferência com implantações de megaempreendimentos, inclusive as atividades de agricultura e de pesca artesanal. Tais interferências são observadas no entorno de complexos portuários ao longo da costa do país, como na região nordeste no Porto de Itaqui, Estado do Maranhão (Carvalho, 2011); no Complexo Industrial Portuário Governador Eraldo Gueiros, em Pernambuco (Castro \& Almeida, 2012); na região sudeste no Porto de Tubarão, Estado do Espírito Santo (Castro \& Almeida, 2012); no Complexo Logístico Industrial do Porto do Açu, no Rio de Janeiro (Pires, 2009; Souza et al., 2009); no Porto de Santos, em São Paulo (Ornelas, 2008); na região sul no Porto de Paranaguá, no Estado do Paraná (Cunha, 2003; Abrahão, 2011); e Porto de Rio Grande, Estado do Rio Grande do Sul (Granato, 2005).

As dinâmicas do estabelecimento de megaempreendimentos, geralmente trazem impactos diversos, considerados pela legislação brasileira em suas dimensões positivas e negativas (CONAMA, 1986). Nesse contexto, impactos causados por megaempreendimentos são distintos e envolvem desde hidrelétricas, transposição de corpos hídricos à construção de complexos portuários. Esta última divisão tem se destacado no mundo e no Brasil pelos distintos impactos ambientais causados durante sua instalação (Castro \& Almeida, 2012).

Na região norte do Estado do Rio de Janeiro foi instalado o Complexo Logístico Industrial do Porto 
do Açu (CLIPA), cuja construção se iniciou em 2007 e suas atividades portuárias em 2015. Nesta região está localizado o $5^{\circ}$ Distrito do Município de São João da Barra cujas comunidades são consideradas tradicionais, uma vez que as práticas da agricultura e da pesca ocorrem de maneira familiar e artesanal (Pires, 2009). Ainda na fase de implantação do CLIPA, tais comunidades sofreram interferências negativas principalmente nos setores da agricultura e da pesca artesanal devido à proibição da atividade de pesca em lagoas costeiras e linha de costa, expulsão de famílias agrícolas devido à incorporação de terras cedidas ao CLIPA, sem desapropriação, alterações dos ecossistemas aquáticos, salinização do lençol freático e do solo decorrente da construção do canal de atracação das embarcações (Pires \& Pedlowski, 2009; Souza \& Oliveira, 2010). Dentre essas, a salinização dos corpos hídricos e do solo pode atingir diretamente as comunidades de agricultores que dependem destes recursos para realizar suas atividades de trabalho.

Salinização pode ser definida como a concentração de sais no solo ou em determinados corpos hídricos, que se torna um fator limitante ao desenvolvimento e produção de plantas (Esteves \& Suzuki, 2008; Pedrotti, et al., 2015). Este processo pode ser gerado naturalmente ou por alterações antrópicas no ambiente, como por exemplo, causada por atividades industriais diversas (Aslam \& Prathapar, 2006; Machado et al., 2007; Lima-Junior \& Silva, 2010). Baseado na problemática da salinização, este trabalho objetiva compreender por meio da etnologia a percepção das comunidades agrícolas do $5^{\circ}$ Distrito do município de São João da Barra, em relação ao processo de salinização dos corpos hídricos e solo decorrente da construção do CLIPA e a viabilidade da atividade agrícola tradicional diante da instalação do megaempreendimento.

\section{Materiais e métodos}

\section{1. Área de estudo}

O $5^{\circ}$ Distrito do município de São João da Barra (Lat. $21^{\circ} 52^{\prime} \mathrm{S}$ e Long $\left.040^{\circ} 55^{\prime} \mathrm{O}\right)$, localizado no norte do Estado do Rio de Janeiro, é formado pelas localidades de Pipeiras, Campo da Praia, Campo de Areia, Sabonete, Barra do Jacaré, Água Preta, Mato Escuro, Cazumbá e Barra do Açu. A área do Distrito está aproximadamente a $30 \mathrm{~km}$ de distância da sede do município.

Tais localidades se configuram como comunidades tradicionais pelo desenvolvimento ancestral das atividades de pesca artesanal, artesanato tradicional e agricultura familiar. Esta última baseada na produção de abacaxi, aipim, quiabo e maxixe (Souza et al., 2009), que estabelece especificidades às comunidades como agrícolas (Ecologus, 2011; Burla et al., 2015).

Na região norte do Estado do Rio de Janeiro foi instalado o Complexo Logístico Industrial Portuário

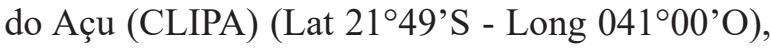
onde se inserem a Zona Industrial do Porto do Açu (ZIPA) e o Distrito Industrial de São João da Barra (DISJB), com aproximadamente 7.036 ha (Ecologus, 2011). A escolha do $5^{\circ}$ Distrito do município de São João da Barra se justifica devido aos impactos, gerados através da instalação do CLIPA, sentidos pelas comunidades tradicionais no desenvolvimento das suas práticas ancestrais de trabalho (Pires, 2009; Souza et al., 2009). 


\subsection{Procedimentos}

Realizou-se 50 entrevistas etnográficas com agricultores familiares entre os meses de junho e outubro de 2015 nas localidades de Cazumbá $(\mathrm{n}=1)$, Barra do Açu ( $(\mathrm{n}=3)$, Mato Escuro $(\mathrm{n}=5)$, Alto do Cardeiro $(n=6)$, Azeitona $(n=8)$, Água Preta $(n=9)$ e Sabonete $(n=18)$. Estas entrevistas foram realizadas a partir de autorização em anuência prévia (Azeredo, 2005) com o representante das comunidades estudadas. Além disso, as entrevistas foram estabelecidas por meio de diálogos, pois deste modo foi facilitada a interação e o estabelecimento de confiança entre entrevistador e entrevistado.

Cada entrevista foi conduzida individualmente com objetivo de minimizar a interferência de outro entrevistado durante o diálogo. O número de entrevistas desenvolvidas no estudo ( $\mathrm{n}=50$ ) justifica-se, pois em estudos etnológicos, em geral, percebe-se que a partir da décima entrevista há um padrão de respostas entre os entrevistados (Mason, 2010).

A pesquisa exploratória foi realizada na primeira etapa de trabalho, a fim de se observar os grupos que seriam estudados: 1) representantes locais das instituições agrícolas: entrevistas relacionadas às dinâmicas agrícolas locais; 2) agricultores: observação das atividades dos trabalhadores nos locais de plantio, além da realização de levantamento de informações acerca dos cultivos. Esta fase ocorreu através da observação participante (Malinowski, 1976), quando foram acompanhadas as atividades relacionadas à agricultura (preparação do solo e sementes, técnicas de plantio e irrigação, colheita e venda dos produtos), além de reuniões públicas com representantes do governo. Nesta fase também foi utilizado um diário de campo que possibilitou registrar informações importantes à pesquisa inicial (Albuquerque et al., 2010). Por meio desta técnica se pretendeu identificar similaridades e diferenças entre as áreas para adequação da linguagem durante as entrevistas e aplicação dos questionários. Além disso, foi utilizado um mapa etnográfico para identificação de áreas possivelmente salinizadas na percepção dos agricultores.

Como sugerido por Sanches (2004), a seleção do primeiro entrevistado ocorreu através de um guia local com conhecimento sobre as dinâmicas dos atores locais. A partir do segundo entrevistado, houve indicação de atores potenciais no contexto da pesquisa pelos membros da comunidade que já tinham respondido ao questionário, a partir da aplicação da técnica bola-de-neve (Bailey, 1982). Além disso, para diminuir o tendenciamento das entrevistas, a técnica de bola de neve foi descontinuada e a coleta de dados foi realizada a partir de eventuais encontros oportunísticos com agricultores (Guba \& Lincoln, 1994).

O vocabulário e expressões locais - conhecidos previamente pelos autores a partir de pesquisas anteriores realizadas na região (Oliveira et al., 2016; Zappes et al., 2016), - foram utilizados durante as entrevistas com o objetivo de estabelecer relação de confiança entre entrevistador e entrevistado (Costa-Neto \& Marques, 2000).

$\mathrm{Na}$ condução das entrevistas foi utilizado um roteiro-padrão contendo questões abertas e fechadas semi-estruturadas, que funcionou como suporte para a obtenção das informações (Albuquerque et al., 2010). Este modelo de entrevista adota um esquema pré-estabelecido, permitindo que adaptações sejam realizadas se necessário pelo entrevistador (Kendall, 2008; Albuquerque et al., 2010), adaptado quando necessário no contexto pesquisado. 
O questionário foi composto de questões associadas ao perfil sociodemográfico dos entrevistados (sexo, idade e escolaridade), espécies cultivadas nas lavouras, possíveis impactos sobre a agricultura tradicional na região, conflitos entre CLIPA e a atividade agrícola, salinização, suas causas e soluções para os conflitos.

\subsection{Análise dos dados}

As descrições das entrevistas foram organizadas segundo a estrutura do questionário aplicado (Ryan \& Bernard, 2000). Estas informações foram fundamentais na descrição do conhecimento tradicional sobre a atividade agrícola local e comparação da percepção dos entrevistados sobre as intervenções em relação a prática, manutenção a viabilidade da atividade agrícola frente às atividades do CLIPA com o conhecimento científico sobre o tema. Para a comparação dos dados foram contabilizadas as frequências percentuais das respostas dos questionários.

Informações sobre as etnoespécies que são cultivadas na agricultura familiar da região foram coletadas junto aos agricultores entrevistados que relataram os nomes populares das principais espécies cultivadas. Tais denominações foram comparadas com a literatura científica a fim de averiguar correlações em relação à nomenclatura, com a indicação da lavoura provável.

\section{Resultados}

\subsection{Perfil dos entrevistados e características da agricultura local}

Na pesquisa, 76\% $(n=38)$ dos entrevistados foram do sexo masculino e $24 \%(n=12)$ do sexo feminino. O perfil etário variou de 20 a 75 anos de idade, sendo: $16 \%(n=8)$ entre 20 a 30 anos; $10 \%$ $(n=5)$ entre 31 a 40 anos; $26 \%(n=13)$ entre 41 a 50 anos; 30\% $(n=15)$ entre 51 a 60 anos; $12 \%(n=6)$ entre 61 a 70 anos e $6 \%(n=3)$ entre 71 a 75 anos. De acordo com o grau de escolaridade, $78 \%(n=39)$ cursaram o ensino fundamental, na maioria das vezes incompleto; $8 \%(\mathrm{n}=4)$ cursaram o ensino médio; $8 \%(n=4)$ não estudaram e $6 \%(n=3)$ não responderam.

A agricultura familiar desenvolvida pelas comunidades do $5^{\circ}$ Distrito do município de São João da Barra apresenta características tradicionais com baixa inserção de modernização tecnológica. Ainda, há intensa utilização de mão-de-obra manual com aplicação de técnicas ancestrais, como: 1) irrigação manual (mangueira pressurizada e bomba) por meio da perfuração de poços artesianos cujas profundidades variam de dois a nove metros em estações úmidas e secas, respectivamente; e 2) utilização de adubo orgânico, lodo, cinza de cana-de-açúcar e rotatividade de culturas.

Os entrevistados classificam as culturas desenvolvidas pela sua morfologia e fisiologia vegetais, sendo descritos dois tipos de lavoura: 'lavoura verde' e 'lavoura branca'. A primeira é composta por hortaliças, enquanto a segunda é formada principalmente por grãos, raízes e frutos. $\mathrm{Na}$ região são cultivadas tradicionalmente várias etnoespécies $(n=13)$ (Tabela 1$)$ e algumas outras espécies diversas, como couve, alface, cebolinha, salsinha, melão, graviola, banana, cana de açúcar, acerola, amora, laranja, goiaba, pimentão, repolho, beterraba, melancia, pepino, mamão, limão, manga e guando. Estas espécies são cultivadas a fim de uti- 
lizar algum espaço entre as lavouras principais em períodos nos quais é necessário o desenvolvimento de rotação de culturas, já que segundo os entrevistados $(\mathrm{n}=38 ; 76 \%)$, esta técnica garante a ciclagem de nutrientes no solo. Ainda, a escolha da espécie a ser plantada é baseada na disponibilidade de espaço para cultivo nas propriedades e na demanda do mercado do norte fluminense.

\subsection{Interferências gerais sobre a agricultura familiar}

Em relação às interferências gerais sobre a atividade agrícola familiar na região, os relatos dos entrevistados se dividiram em: aumento da salinização ( $\mathrm{n}=24 ; 48 \%)$, dificuldade financeira $(n=24 ; 48 \%)$, período de estiagem $(n=18 ; 36 \%)$ e ocorrência de doenças nas lavouras $(n=3 ; 6 \%)$ (Figura 1). Ainda, $6 \%(\mathrm{n}=3)$ descreveram que não existem interferências e 4\% (n=2) desconhecem interferências sobre a atividade. A salinização dos corpos hídricos e do solo e a dificuldade financeira se mostram como as interferências mais marcantes na percepção dos agricultores.

Em relação às causas da salinização, $24 \%$ $(\mathrm{n}=12)$ dos agricultores atribuíram à instalação do CLIPA na região; $18 \%(\mathrm{n}=9)$ relataram que o fenômeno ocorre naturalmente sem a interferência humana; $4 \%(\mathrm{n}=2)$ citaram que as causas podem ser tanto de atividades do CLIPA quanto um fenômeno

TABELA 1 - Principais cultivos desenvolvidos na prática agrícola familiar do $5^{\circ}$ Distrito do município de São João da Barra, norte do Estado do Rio de Janeiro.

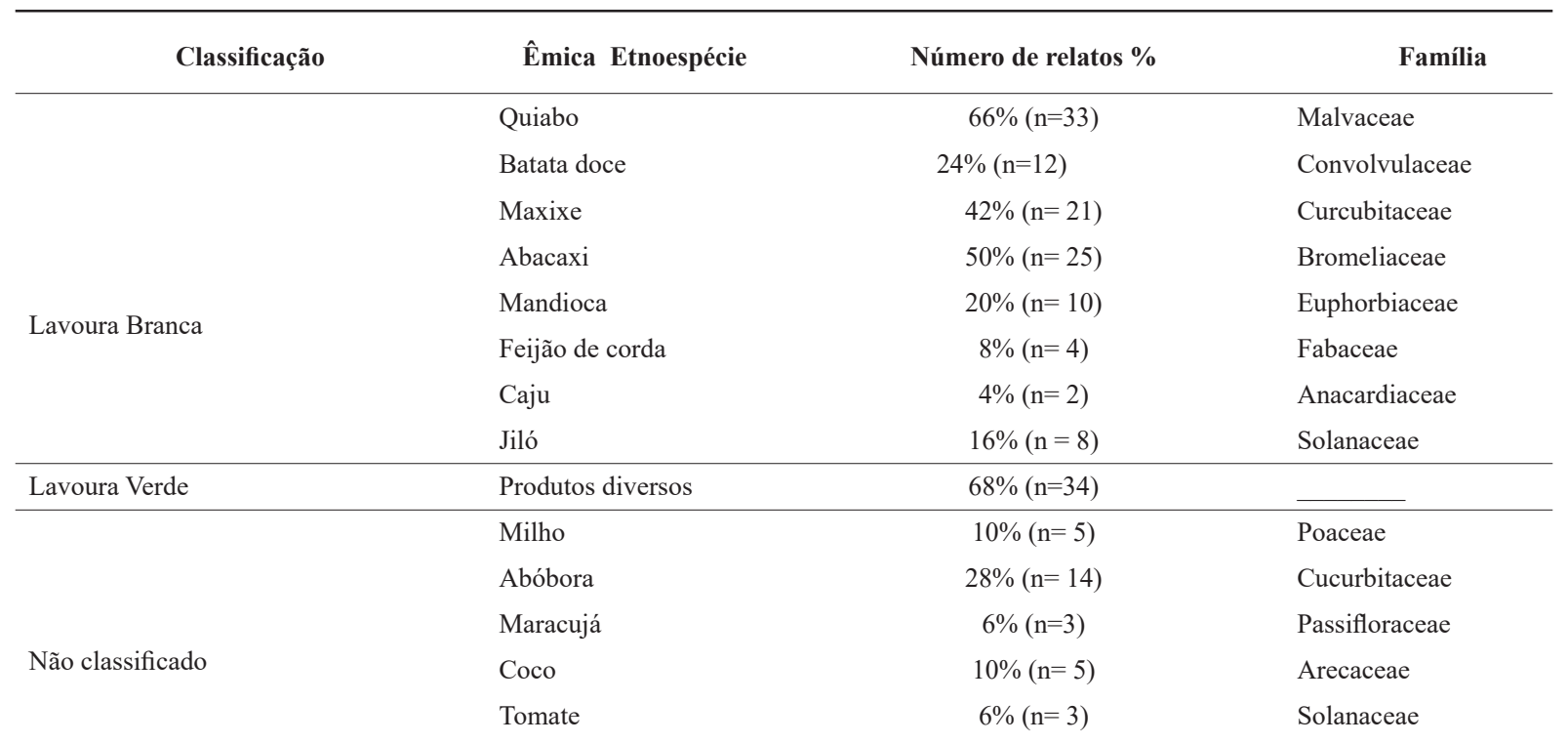

FONTE: Pereira et al. (2004); Cardoso et al. (2005); Embrapa Hortaliças (2008); Oliveira et al. (2012); Nascimento et al. (2013). 
natural (Figura 2). Os agricultores explicaram que alguns trabalhadores da área desconhecem sobre a salinização e suas causas, pois as comunidades não são informadas sobre as alterações que ocorrem na região, principalmente após a instalação do
CLIPA. Os entrevistados que citaram a ocorrência da salinização na área explicaram que durante as instalações do CLIPA foi aberto um grande canal inserido no continente (ver Figura 4) por onde os navios atracam e descarregam as cargas. Segundo

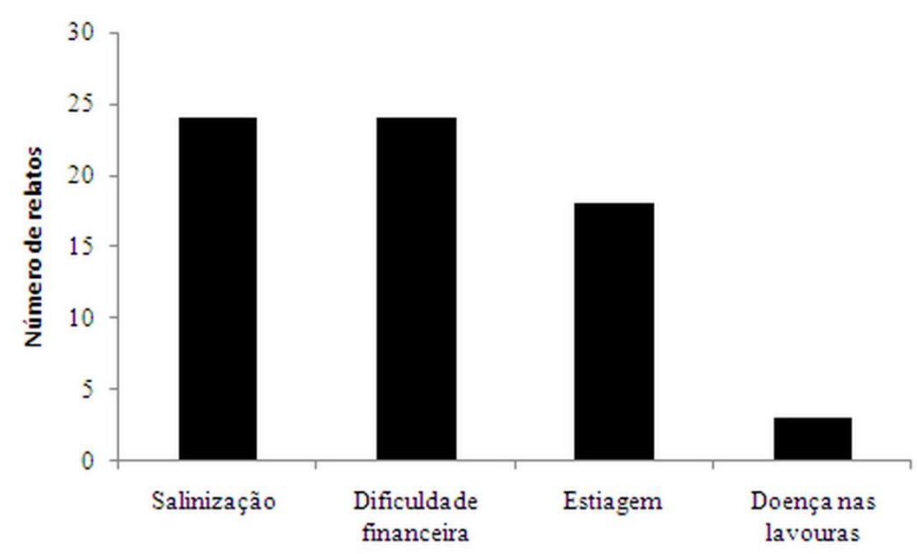

FIGURA 1 - Percepção de agricultores referente às interferências gerais sobre a atividade agrícola familiar no $5^{\circ}$ Distrito, município de São João da Barra, norte do Estado do Rio de Janeiro.

FONTE: Organização dos autores (2016).

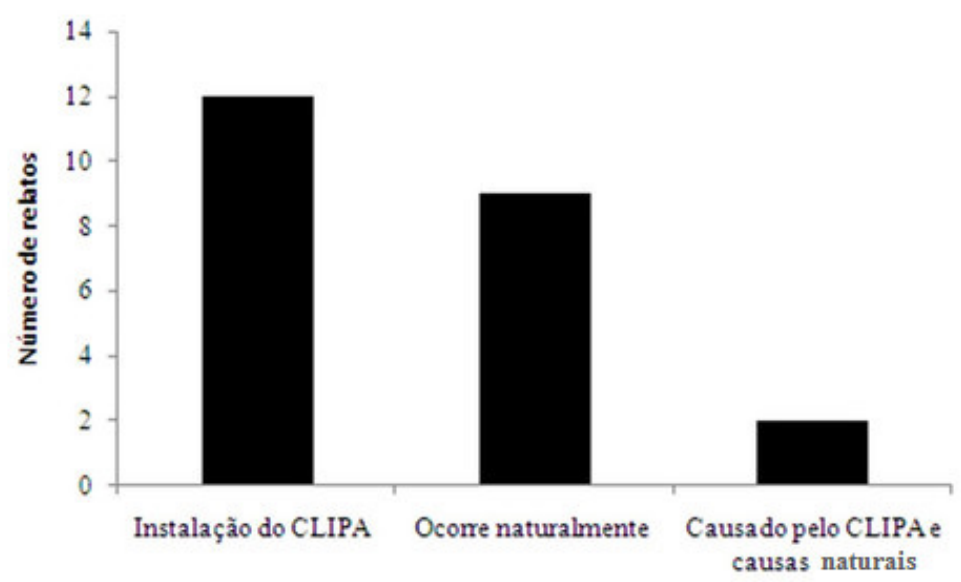

FIGURA 2 - Percepção de agricultores referente às causas da salinização dos corpos hídricos e do solo no $5^{\circ}$ Distrito, município de São João da Barra, norte do Estado do Rio de Janeiro.

FONTE: Organização dos autores, 2016. 
estes agricultores, tal obra intensificou o teor de sal na rede hídrica local e no solo o que consequentemente interferiu na agricultura local.

Dentre os entrevistados que citaram a salinização dos corpos hídricos e do solo como uma das interferências sobre a agricultura familiar $(n=24)$, as principais consequências sofridas são a 'baixa fertilidade' ( $\mathrm{n}=6 ; 12 \%)$, a 'morte das plantas' $(\mathrm{n}=14$; $28 \%$ ) e a sequência 'baixa fertilidade seguida da morte das plantas' ( $\mathrm{n}=2 ; 4 \%$ ) (Figura 3). Dois entrevistados (4\%) não souberam descrever as principais consequências. Estas podem induzir o resultado final de perda de toda a lavoura e/ou o aumento dos custos da produção. Ainda, os entrevistados indicaram as áreas salinizadas na região próxima às comunidades de Mato Escuro, Alto do Cardeiro, Azeitona, Água Preta e áreas no entorno dos canais São Bento e nas proximidades da localidade de Sabonete (Figura 4).

Os entrevistados $(\mathrm{n}=7 ; 14 \%)$ descreveram que não existe uma solução para o problema da saliniza- ção sobre as lavouras, mas que a fim de minimizar as interferências negativas deste fenômeno algumas alternativas podem ser realizadas:

1) para a salinização: plantio das culturas em lugares mais altos a fim de evitar o solo salinizado, já que o excesso de sal se torna um fator limitante ao crescimento das plantas;

2) para as dificuldades financeiras: busca de novos fregueses, recorrer a incentivos governamentais, evitar contratação de trabalhadores externos, trabalhar em outras atividades, empréstimos com amigos para honrar dívidas e arrendamento de terras por falta de trabalhadores;

3) para a estiagem: irrigação e adubação intensas e aprofundamento dos poços artesianos, sendo esta a principal técnica tradicional utilizada para irrigação na região;

4) para as doenças nas lavouras: receita de remédio caseiro e aquisição de sementes comercializadas.

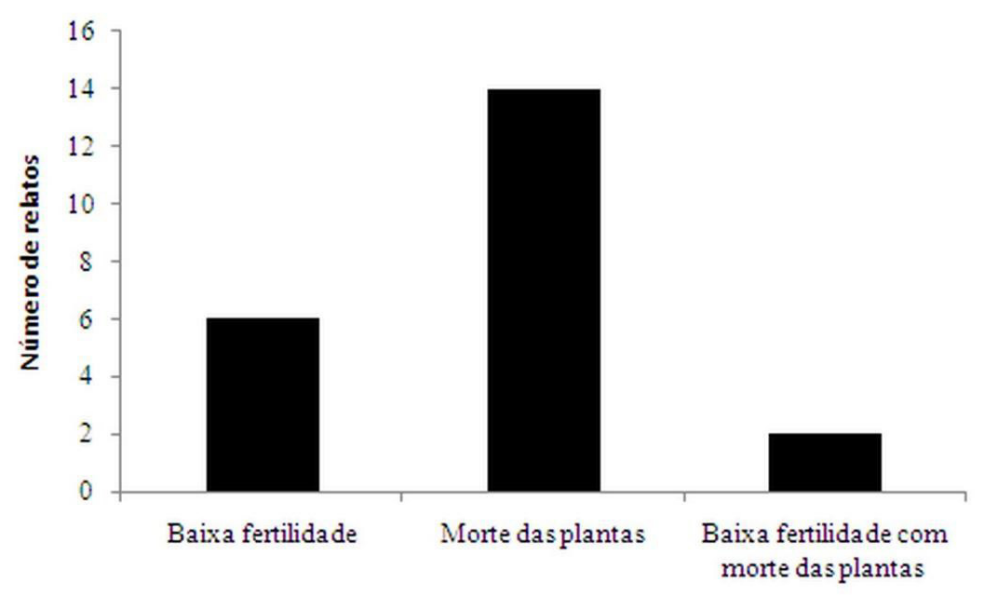

FIGURA 3 - Percepção de agricultores referente às principais consequências da salinização dos corpos hídricos e do solo sobre a agricultura familiar no $5^{\circ}$ Distrito, município de São João da Barra, norte do Estado do Rio de Janeiro.

FONTE: Organização dos autores, 2016. 


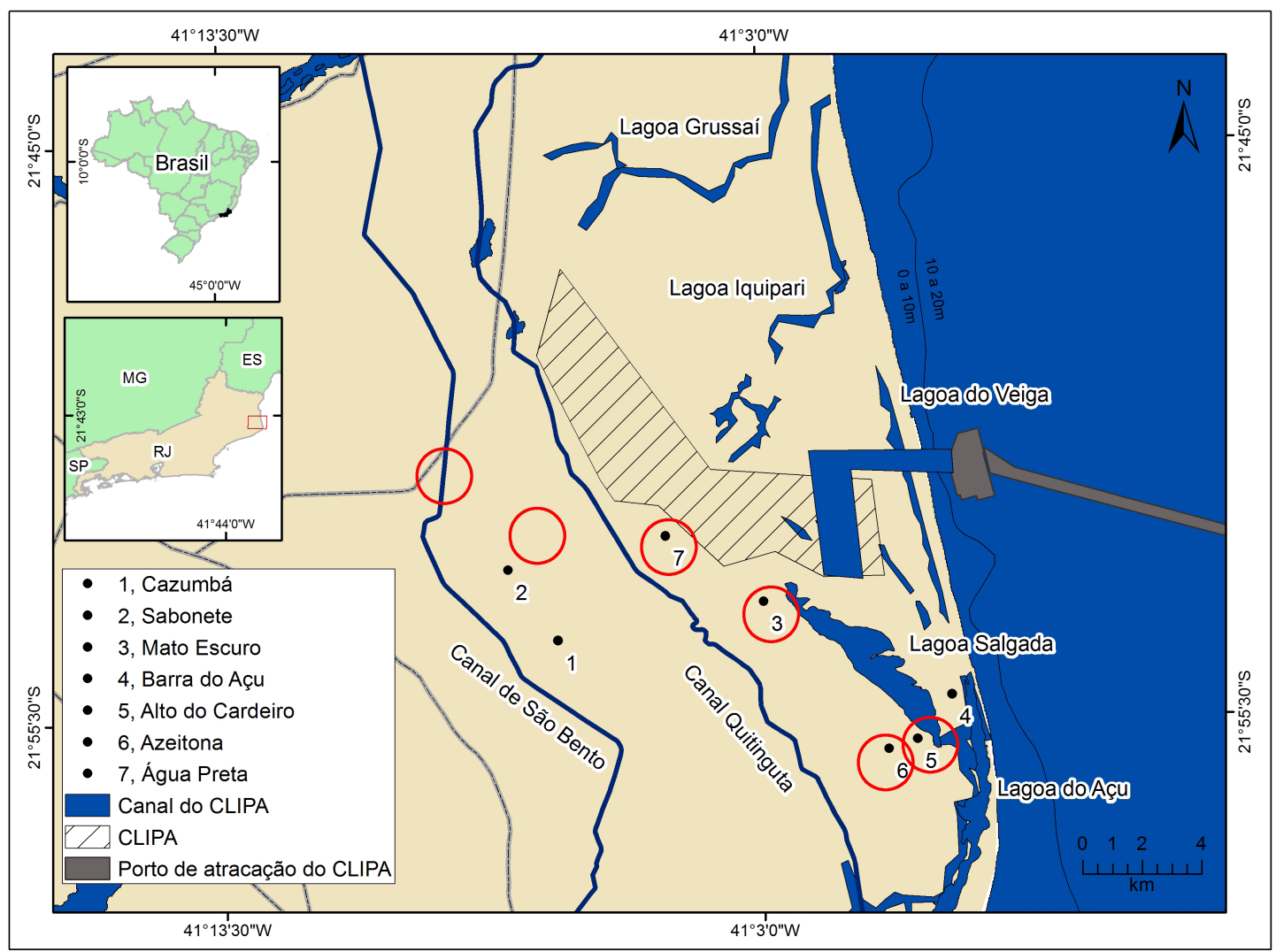

FIGURA 4 - Indicação das localidades pesquisadas, espacialidade dos corpos hídricos locais, Complexo Logístico Industrial do Porto do Açu (CLIPA) e identificação das áreas salinizadas indicadas pelos agricultores (representadas em círculos), $5^{\circ}$ Distrito, município de São João da Barra, norte do Estado do Rio de Janeiro.

FONTE: Organização dos autores, 2016.

\section{Discussão}

As comunidades rurais do $5^{\circ}$ Distrito do município de São João da Barra, norte fluminense, praticam ancestralmente a atividade agrícola familiar. Estas, majoritariamente, se caracterizam por seus integrantes serem do sexo masculino e com baixo nível de escolaridade. Tais características se mostram comuns aos trabalhadores rurais no Brasil (Camarano et al., 1999; Ney \& Hoffmann, 2009). A baixa escolaridade interfere na situação socioeconômica das famílias que dependem da agricultura familiar, o que consequentemente interfere na sua capacidade de organização como grupo, além de impedir sua inserção em vagas de emprego oferecidas no CLIPA (Pires, 2009). 
$\mathrm{Na}$ região, as atividades do CLIPA delimitaram áreas antes utilizadas pelos agricultores, o que afetou o modo de vida das comunidades estudadas. De maneira geral, os sistemas tradicionais de acesso aos recursos naturais são excluídos com a instalação de megaempreendimentos no entorno destas comunidades (Pires, 2009). As relações sócio-culturais no campo, com destaque para a transmissão dos direitos às propriedades, devem ser analisadas especificamente para cada região, já que os contextos geográfico, institucional, econômico e social se estabeleceram historicamente.

Em relação às etnoespécies (lavoura branca e lavoura verde) descritas como principais cultivos da região, estas são consideradas como tradicionais na agricultura familiar (Burla et al., 2015). Os agricultores se referem a essas espécies como aquelas que melhor se adequam às condições físicas da região. Historicamente a maior parte da produção agrícola do norte fluminense é fornecida às Centrais de Abastecimento do Estado (CEASA) do município do Rio de Janeiro (Silva \& Carvalho, 2004). Atualmente, essa distribuição ainda se mantém, mas uma parcela da produção é revendida em Campos dos Goytacazes, município próximo a São João da Barra. Ainda, as espécies selecionadas para o plantio e posteriormente vendidas são baseadas na demanda do mercado, o que demonstra ser a atividade de agricultura familiar uma fonte de renda das famílias agricultoras do $5^{\circ}$ Distrito de São João da Barra que dependem de uma cadeia produtiva que abastece a região norte fluminense e outras áreas do país, que é comum na produção agrícola familiar do Brasil (Dorow et al., 2017).

Neste estudo, os entrevistados citaram que realizam a rotatividade de culturas a fim de aproveitar os espaços entre as lavouras e diminuir o problema da ciclagem de nutrientes. Ao longo dos anos, cultivos contínuos de mesmas espécies causam queda na produtividade, pois as características do solo são alteradas e as condições do ambiente propiciam multiplicação de pragas e doenças nos cultivos. Desta maneira, a rotatividade de culturas se torna a solução para minimizar estes problemas (Silveira \& Stone, 2003). Isto demonstra que existe uma convergência entre o conhecimento tradicional dos agricultores do $5^{\circ}$ Distrito do município de São João da Barra e o conhecimento científico sobre o tema, o que indica que estes dois tipos de saberes podem ser trabalhados juntos na busca de soluções de problemas voltados à questão agrária no norte fluminense.

As principais interferências negativas sobre a atividade agrícola familiar relatadas pelos agricultores entrevistados se relacionam diretamente a salinização do solo e dos mananciais hídricos, questões financeiras, além de estiagem e doenças nas plantações. Questões financeiras podem estar diretamente relacionadas à salinização, já que este fenômeno pode levar à perda dos cultivos devido à concentração de sais no solo limitar a produção de plantas (Esteves \& Suzuki, 2008; Pedrotti et al., 2015).

$\mathrm{Na}$ visão dos agricultores, o processo de salinização do solo e dos mananciais hídricos do $5^{\circ}$ Distrito do município de São João da Barra e em outras comunidades do entorno acontece por causa da atividade humana, mas também está sujeita a dinâmicas naturais, esta última devido à proximidade com o mar e o regime de marés (Lima et al., 2001). Já a ação antrópica está diretamente relacionada à construção do CLIPA. Segundo os entrevistados, a salinidade da região pode ter se intensificado com 
a construção do canal de atracação dos navios do CLIPA.

Para a construção desse canal foi realizado um aterro hidráulico com aproximadamente 44 metros cúbicos, cujo material se originou da dragagem do canal de navegação aberto para a implantação da Unidade de Construção Naval - UCN do megaempreendimento (Latini, 2016). Tal obra pode ter alterado a dinâmica físico-química dos corpos hídricos e do solo das áreas de cultivo localizadas no entorno do megaempreendimento. Para a construção deste tipo de canal é necessária uma dragagem a fim de limpar, aprofundar e escavar o fundo das áreas marítimas próximas aos espaços de atracagem dos navios. Essa atividade gera alterações na turbidez, salinidade e contaminação química dos corpos hídricos e em algumas situações podem não ser consideradas no planejamento e nem divulgadas à população (Porto \& Teixeira, 2002; Castro \& Almeida, 2012).

$\mathrm{O}$ fato de alguns entrevistados desconhecerem a salinização e suas causas está relacionado a pouca informação recebida pelas comunidades. No início e durante a instalação do CLIPA foram realizadas audiências públicas previstas em lei, mas a participação ativa da população foi obstruída por meio da restrição de acesso aos documentos relacionados ao megaempreendimento e uso de terminologia técnica pouco compreendida pelo público leigo (Pires, 2009; Ditty \& Rezende, 2013). As práticas socioculturais bem como a linguagem local devem ser consideradas na facilitação da comunicação de massa, principalmente quando tais informações podem interferir na manutenção das atividades locais (Alexandre, 2001). No Brasil, as audiências públicas, inseridas nos processos de Licenciamento Ambiental, estão sendo subutilizadas além das in- formações ambientais não serem prévias e efetivas (Coletti, 2012).

Como consequências da salinização sobre a agricultura familiar, os entrevistados descrevem que ocorre a baixa fertilidade e morte das plantas, já que tanto o solo quanto a água utilizada para irrigação estão com alto teor salino. Isso eleva os custos da produção e diminui o lucro dos agricultores. Para os entrevistados não existe uma solução direta para este problema, mas sim alternativas que envolvem desde a mudança da área do plantio, aumento da rede de clientes, diminuição de gastos e uso de técnicas tradicionais de irrigação e adubação. Segundo Aslam \& Prathapar (2006), comunidades agrícolas paquistanesas afetadas pela salinização testaram medidas que diminuíram as dificuldades de irrigação por sulcos, bacias de papelão ondulado, por aspersão e por gotejamento. No entanto, tais técnicas foram utilizadas apenas pelos grandes proprietários de terra que possuíam maquinário e pessoal capacitado para a realização das mesmas. Assim, a baixa escolaridade aliada à ausência de equipamentos adequados às novas técnicas dificulta a manutenção da agricultura familiar. Neste contexto, é possível perceber que as pequenas comunidades agrícolas paquistanesas e os agricultores familiares do $5^{\circ}$ Distrito de São João da Barra se assemelham nas dificuldades voltadas à atividade, embora estejam distantes geograficamente.

Os agricultores indicaram no mapa as áreas salinizadas, o que demonstra que além de identificarem o solo e corpos hídricos enquanto recursos econômicos, identificam também as características físicas e químicas do sedimento, as alterações sobre tais características e os efeitos causadores destas. Todo este conhecimento é resultado das territorialidades históricas sobrepostas e materializadas no 
espaço (Veronezzi \& Fajardo, 2015). Na percepção dos entrevistados, a salinização apesar de ser natural para a região foi intensificada após a instalação do CLIPA e atualmente interfere na manutenção da prática agrícola. As áreas apontadas no mapa se localizam nas proximidades do megaempreendimento, mas também estão situadas próximo à costa o que as torna naturalmente salinas devido à proximidade com o mar (Lima et al., 2001). Esta salinidade é intensificada em períodos de baixa precipitação (Pedrotti et al., 2015). Entretanto, Latini (2016) apresenta resultados da intensificação evidente da salinização do solo e corpos hídricos causados após a instalação do CLIPA. Neste estudo, análises limnológicas e pedológicas mostram a intensificação desse fenômeno nas mesmas áreas identificadas no mapa pelos agricultores. O Estudo de Impacto Ambiental - EIA (Ecologus, 2011) realizado aborda a salinização de maneira introdutória, apontando a área como naturalmente salobra e que por essa razão a recuperação de alteração salina poderia ser minimizada naturalmente. Isto demonstra a necessidade da continuidade de estudos com estas abordagens que juntamente com pesquisas etnopedológicas podem buscar soluções para a salinização no norte fluminense e desta maneira manter a agricultura familiar na região por meio da junção de técnicas dos conhecimentos tradicional e científico.

Altas taxas de sais presentes nos recursos hídricos e solos têm sido identificadas em todo o mundo, principalmente nas regiões áridas e semiáridas onde as consequências afetam a disponibilidade de água potável para produção de alimentos e dessedentação (Vengosh et al., 2000; Pedrotti, et al, 2015; Zanotti, 2015). Tais identificações contribuem para entender os relatos das comunidades agrícolas pesquisadas em São João da Barra quando expõem a diminuição da fertilidade dos solos cultivados e a morte de algumas espécies devido à salinização.

Uma questão a ser considerada é o fato de que governantes e grandes empresários do norte fluminense apresentam como meta extinguir a economia tradicional como justificativa para a construção de uma sociedade economicamente rica e igualitária (Ribeiro, 2010). Ainda, as políticas públicas socioambientais da zona costeira no Estado não direcionam esforços a fim de garantir o equilíbrio entre o desenvolvimento socioeconômico e a conservação do patrimônio natural e cultural (Souza \& Oliveira, 2010). Esta realidade intensifica a crise social e ambiental que envolve comunidades do entorno de empreendimentos dessa natureza. Os meios legislativos são manipulados a fim de manter o interesse dos proponentes portuários privados (Sahoo, 2014), o que consequentemente não considera os interesses do coletivo. Neste sentido, mostra-se necessário um programa de incentivos para o fortalecimento da agricultura familiar no país (Buainaim et al., 2003; Ribeiro, 2010). Tal programa deve ser elaborado por meio de estratégias de inclusão dos agricultores em áreas de conflito com empreendimentos, já que tais atores geralmente são marginalizados pela falta de políticas de apoio (Buainaim et al., 2003).

\section{Conclusão}

As comunidades de agricultores familiares do $5^{\circ}$ Distrito do município de São João da Barra são caracterizadas como tradicionais por desenvolverem suas práticas de relação com a natureza de maneira ancestral sendo repassadas entre seus membros. $\mathrm{O}$ conhecimento tradicional exibido pelos entrevistados em relação às alterações sofridas pelo ambiente 
e técnicas utilizadas para a qualidade de cultivos apresenta semelhança ao conhecimento científico.

A continuidade da atividade agrícola familiar na região pode estar comprometida devido à intensificação da salinização dos corpos hídricos e solo. Tal salinização é um fenômeno natural devido às características da costa norte fluminense, mas pode ter sido intensificado após a instalação do CLIPA. A perda das lavouras causa prejuízo financeiro às famílias locais que dependem desta atividade para sua sobrevivência financeira. As lavouras estão sediadas principalmente na área de influência direta do megaempreendimento, o que aumenta a interferência sobre o cotidiano dos atores locais que dependem da agricultura familiar.

Estudos geográficos, etnográficos, pedológicos e limnológicos devem ser realizados na região a fim de buscar soluções para os conflitos entre agricultura familiar e CLIPA por meio das demandas das próprias populações. Diante deste cenário, o poder público, a iniciativa privada responsável pelo megaempreendimento portuário e as instituições de pesquisa da região devem planejar o desenvolvimento sócio-econômico-cultural com a participação da comunidade interessada a fim de manter a qualidade de vida local.

\section{Agradecimentos}

Aos agricultores e funcionários da Prefeitura de São João da Barra pela colaboração durante as coletas dos dados. A primeira autora agradece à Coordenação de Aperfeiçoamento de Pessoal de Nível Superior - Brasil (CAPES) - Código de Financiamento 001 pela concessão de bolsa de mestrado. O segundo autor agradece à Coordenação de Aperfeiçoamento de Pessoal de Nível Superior - Brasil (CAPES) - Código de Financiamento 001 pela concessão de bolsa de doutorado. A terceira autora agradece à Fundação Carlos Chagas Filho de Amparo à Pesquisa do Estado do Rio de Janeiro (FAPERJ) (E 26/203.202/2016) e Conselho Nacional de Desenvolvimento Científico e Tecnológico (CNPq) (Processo 400053/2016-0) pelo fomento à pesquisa.

\section{Referências}

Abrahão, C. M. de S. Porto de Paranaguá: Transformações Espaciais decorrentes do processo de Modernização Capitalista Integração Territorial entre os anos 1970 e 2010. Tese (Doutorado) - Programa de Pós-Graduação em Geografia, Setor de Ciências da Terra. Universidade Federal do Paraná, Curitiba, 2011.

Agrawal, A. Indigenous and scientific knowledge: some critical comments. Development and change, 26(3), 413439, 1995.

Albuquerque, U. P.; Lucena, R. F. de P.; Alencar, N. L. L. Métodos e técnicas para coleta de dados etnobiológicos. In: Albuquerque, U. P.; Lucena, R. F. de P.; Cunha, L. V. F. C. Métodos e técnicas na Pesquisa Etnobiológica e Etnoecológica. Série Estudos Avançados: NUPPEA, 2010. p. 39-64.

Alexandre, M. O papel da mídia na difusão das representações sociais. Comum, 6(17), 111-125, 2001.

Aslam, M.; Prathapar, S. A. Strategies to mitigate secondary salinization in the Indus Basin of Pakistan: A selective review. Sri Lanka: IWMI, 2006.

Azeredo, C. M. A. A regulamentação do acesso aos recursos genéticos e aos conhecimentos tradicionais associados no Brasil. Biota Neotropica, 5(1), 2005.

Bailey, K. D. Methods of social research. 2 ed., New York: McMillan Publishers. The Free Press, 1982. 533p.

Buainain, A. M.; Romeiro, A. R.; Guanzirol, C. Agricultura Familiar e o Novo Mundo Rural. Revista Sociologias, 5(10), 
312-347, 2003. Disponível em: <http://www.scielo.br/pdf/ soc/n10/18723.pdf>

Burla, R. da S.; Oliveira, V. de P. S. de; Manhães, C. M. C.; Francelino, F. M. A.; Santos, J. C. O. R.; Colucci, M. C.; Fontes, S. C. Caracterização dos aspectos socioeconômicos e do processo produtivo agrícola dos produtores rurais da microbacia do Rio Doce, São João da Barra, RJ. Vértices, 17(1), 149-162, 2015. Disponível em: <http://essentiaeditora.iff.edu.br/index.php/vertices/article/view/18092667.20150010>

Camarano, A. A.; Abramovay, R. Êxodo rural, envelhecimento e masculinização no Brasil: panorama dos últimos cinquenta anos. Revista Brasileira de Estudos de População, 15(2), 45-65, 1999. Disponível em: <http:// www.abep.nepo.unicamp.br/docs/rev_inf/vol15_n2_1998/ vol15_n2_1998_4artigo_45_65.pdf $>$

Cardoso, A. D.; Viana, A. E. S.; Ramos, P. A. S.; Matsumoto, S. N.; Amaral, C. L. F.; Sediyama, T.; Morais, O. M. Avaliação de clones de batata-doce em Vitória da Conquista. Horticultura Brasileira, 23(4), 911-914, 2005. Disponível em: <www.scielo.br/pdf/hb/v23n4/a09v23n4.pdf>

Carvalho, F. C. de. Gestão do território, lugar e conflitos socioambientais: o caso da Usina Termelétrica Porto do Itaqui em São Luís, MA. Dissertação (Mestrado em Geografia) - Departamento de Geografia, Universidade de Brasília, Brasília, 2011.

Castro, S. M.; Almeida, J. R. Dragagem e conflitos ambientais em portos clássicos e modernos: uma revisão. Sociedade \& Natureza, 24(3), 519-533, 2012. Disponível em: $<$ http://www.seer.ufu.br/index.php/sociedadenatureza/ article/view/17200>

Coletti, R. N. A participação da sociedade civil em instrumentos da política ambiental brasileira. Desenvolvimento e Meio Ambiente, 25, 39-51, 2012. Disponível em: < http:// revistas.ufpr.br/made/article/view/25544/18572>

CONAMA - Conselho Nacional do Meio Ambiente. Resolução $n^{\circ}$ 001, de 23 de janeiro de 1986. Dispõe sobre critérios básicos e diretrizes gerais para o Relatório de Impacto Ambiental - RIMA. Diário Oficial da República Federativa do Brasil. Brasília, DF, 17 fev. 1986.

Costa-Neto, E. M.; Marques, J. G. W. A Etnotaxonomia de recursos ictiofaunísticos pelos pescadores da comunidade de Siribinha, Norte do Estado da Bahia, Brasil. Biociencias, 8(2), 61-76, 2000.

Cunha, Í. Conflito ambiental em águas costeiras: Relação porto - cidade no Canal de São Sebastião. Ambiente \& Sociedade, 6(2), 2003. Disponível em: <http://www.scielo. br/pdf/asoc/v6n2/a06v06n2.pdf>

Diegues, A. C. Etnoconservação da natureza: enfoques alternativos. In: Diegues, A. C. (Org.). Etnoconservação: novos rumos para a proteção da natureza nos trópicos. São Paulo: Hucitec, 2000.

Ditty, J. M.; Rezende, C. E. de. Public participation, artisanal fishers, and the implantation of a coastal megaproject. Sociedade \& Natureza, 25(1), 51-60, 2013. Disponível em: <http://www.scielo.br/scielo.php?pi$\mathrm{d}=\mathrm{S} 1982-45132013000100005 \&$ script $=$ sci_arttext $>$

Dorow, R.; Uller-Gómez, C.; Bauer, E. Estratégias de valorização dos produtos da agricultura tradicional em Biguaçu, SC: perspectivas de mercado e conservação ambiental. Desenvolvimento e Meio Ambiente, 40, 365-383, 2017. Disponível em: < http://revistas.ufpr.br/made/article/ view/45926/32115>

Ecologus. RIMA. Relatório de Impacto Ambiental - Infraestruturas do Distrito Industrial de São João da Barra. s. 1.: LLX, Ecologus, Agrar, maio 2011. Disponível em:< http:// ceivap.org.br/downloads/eia-rima-distrito-industrial-de-sao-joao-da-barra.pdf $>$ Acesso em: 10 jan. 2015.

Embrapa Hortaliças. Hortaliças em números. 2008. Disponível em: <http://www.cnph.embrapa.br/paginas/ hortalicas_em_numeros.htm>.Acessado em: 11 dez. 2015.

Esteves, B. dos S.; Suzuki, M. S. Efeito da salinidade sobre as plantas. Oecologia Brasiliensis, 12(4), 6, 2008. Disponível em: < https://dialnet.unirioja.es/descarga/articulo/2883337.pdf $>$

Granato, F. C. Subsídios técnicos para o estabelecimento de um plano de gerenciamento ambiental integrado do processo de dragagem do Porto de Rio Grande-RS. 2005. Tese (Doutorado) - Programa de Pós-Graduação em Oceanografia Física, Química, e Geológica. Fundação Universidade Federal do Rio Grande. Rio Grande, 2005. 
Guba, E. G.; Lincoln, Y. S. Competing Paradigms in Qualitative Research. In: Denzin, N. K.; Lincoln, Y. S. Qualitative Research. London; New Delhi: Sage, 1994.

Lima-Junior, J. A. de; Silva, A. L. P. da. Estudo do processo de salinização para indicar medidas de prevenção de solos salinos. Enciclopédia Biosfera, 6(11), 2010. Disponível em: $<$ http://www.conhecer.org.br/enciclop/2010c/estudo $\% 20$ do $\% 20$ processo.pdf $>$

Kendall, L. The conduct of qualitative interviews: Research, Questions, Methodological Issues, and Researching Online. In: Coiro, J.; Knobel, M.; Lankshear, C.; Leu, D. J. Handbook of research on new literacies, p. 133-149, 2008.

Latini, J. R. A avaliação de impacto ambiental (AIA) enquanto instrumento participativo e preventivo no contexto do neodesenvolvimento: o caso do Complexo Logístico Industrial do Porto do Açu (CLIPA). 2016. 148f. Dissertação (Mestrado) - Centro de Biociências e Biotecnologia. Universidade Estadual do Norte Fluminense - Darcy Ribeiro, Campos dos Goytacazes, 2016.

Lima, N. R. W.; Bizerril, C. R. S. F.; Caniçali, M. R.; Suzuki, M. S.; Assumpção, J. Atividade de pesca durante a abertura da barra da Lagoa de Iquipari, São João da Barra, RJ. Boletim do Instituto de Pesca, 27(2), 191-200, 2001. Disponível em: <ftp://ftp.sp.gov.br/ftppesca/27\%5B2\%5D-art_09.pdf>

Machado, R.; Netto, A. de O. A.; Campeche, L. F. de S. M.; Barros, A. C. Efeito da salinidade em características físico-hídricas em solos salino-sodilizados no perímetro irrigado Jabiberi-SE. Revista Brasileira de Agricultura Irrigada, 1(1), 15-19, 2007. Disponível em: <http://www.inovagri. org.br/revista/index.php/rbai/article/view/8>

Malinowski, B. Argonautas do Pacifico ocidental: um relato do empreendimento e da aventura dos nativos nos arquipélagos da Nova Guiné Melanésia. V. Civita, 1976.

Mason, M. Sample Size and Saturation in PhD Studies Using Qualitative Interviews. Forum: Qualitative Social Research; Social Fourschung. v. 11, n. 3, sep./2010.

Nascimento, I. B.; Ferreira, L. E.; Medeiros, J. F. de; Aroucha, E. M. M.; Souza, C. M. G.; Cavalcanti, N. K.; Izídio, N. S. de C. Qualidade pós-colheita de quiabo submetido a diferentes lâminas de água salina. Agropecuária Cientifica no Semiárido, 9(2), 88-93, 2013. Disponível em: <http://150.165.111.246/ojs-patos/index.php/ACSA/ article/view/277>

Ney, M. G.; Hoffmann, R. Educação, concentração fundiária e desigualdade de rendimentos no meio rural brasileiro. Revista de Economia e Sociologia Rural, 47(1), 147-181, 2009. Disponível em: $<$ http://www.scielo.br/scielo.php?script=sci_arttext\&pid=S0103-20032009000100006>

Oliveira, F. de A.; Oliveria, M. K. T. de; Lima, L. A.; Bezerra, F. M. S.; Cavalcante, A. L. G. Desenvolvimento inicial do maxixeiro irrigado com águas de diferentes salinidades. Agropecuária Científica no Semiárido, 8(2), 22-28, 2012. Disponível em: <http://150.165.111.246/ojs-patos/ index.php/ACSA/article/view/175>

Oliveira, P. da C.; Di Benedito, A. P. M.; Bulhões, E. M. R.; Zappes, C. A. Artisanal fishery versus port activity in southern Brazil. Ocean \& Coastal Management, 129, 4957, 2016.

Ornelas, R. dos S. Relação porto/cidade: o caso de Santos. Tese (Doutorado). Universidade de São Paulo, São Paulo, 2008.

Pedrotti, A.; Chagas, R. M.; Ramos, V. C.; Prata, A. P. do N.; Lucas, A. A. T.; Santos, P. B. dos. Causas e consequências do processo de salinização dos solos. Revista Eletrônica em Gestão, Educação e Tecnologia Ambiental, 19(2), 1308-1324, 2015. Disponível em: <http://cascavel.ufsm. br/revistas/ojs-2.2.2/index.php/reget/article/view/16544>

Pereira, B. E.; Diegues, A. C. Conhecimento de populações tradicionais como possibilidade de conservação da natureza: uma reflexão sobre a perspectiva da etnoconservação. Desenvolvimento e Meio Ambiente, 22, 37-50, 2010. Disponível em: <revistas.ufpr.br/made/article/download/16054/13504>

Pereira, R. C.; Oliveira, M. T. R.; Lemos, G. C. S. Plantas utilizadas como medicinais no município de Campos de Goytacazes-RJ. Revista Brasileira de Farmacognosia, 14, 37-40, 2004. Disponível em: <http://www.scielo.br/pdf/ rbfar/v14s0/a15v14s0.pdf>

Pires, B. de O.; Pedlowski, M. A. Impactos socioambientais de mega-empreendimentos: o caso do complexo portuário da Barra do Açu/RJ. In: Anais do Congresso Brasileiro de Sociologia, Rio de Janeiro, RJ, 2009. 
Pires, B. de O. Transformação produtiva de espaços rurais e seus impactos sobre populações locais: uma análise da construção do Complexo Portuário Industrial do Açu no munícipio de São João da Barra, RJ. Dissertação (Mestrado) - Centro de Ciências do Homem. Universidade Estadual do Norte Fluminense, Campos dos Goytacazes, 2009.

Porto, M. M.; Teixeira, S. G. Portos e o desenvolvimento. São Paulo: Lex Editora, 2002.

Queiroz, H. L. A reserva de desenvolvimento sustentável Mamirauá. Estudos Avançados, 19(54), 183-203, 2005. Disponível em: $<$ http://www.scielo.br/scielo.php?script=sci_arttext\&pid=S0103-40142005000200011>

Resende, M.; Curi, N.; Rezende, S. B.; Corrêa, G. F. Pedologia: base para distinção de ambientes. Viçosa: NEPUT, 1995.

Ribeiro, R. V. Desafios ao desenvolvimento regional do Norte Fluminense. Dissertação (Mestrado) - Programa de Pós-Graduação em Políticas Públicas, Estratégias e Desenvolvimento. Universidade Federal do Rio de Janeiro, Rio de Janeiro, 2010.

Ryan, G. W.; Bernard, H. R. Data management and analysis methods. In: Denzin, N. K.; Lincoln, Y. S. Handbook of qualitative research. 2. ed. London; New Delhi: Sage, 2000.

Sahoo, K. Deregulation in development project: A case of Dhamra port project in Odisha. Ocean \& Coastal Management, 100, 151-158, 2014.

Sanches, R. A. Caiçaras e a estação ecológica de Jureia-Itatins: litoral sul de São Paulo. São Paulo: Annablume, 2004.

Silva, R. C. R. S. da; Carvalho, A. M. de. Formação econômica da Região Norte Fluminense. In: Pessanha, R. M.; Neto, R. e S. (Orgs.). Economia e desenvolvimento no Norte Fluminense: da cana-de-açúcar aos royalties do petróleo. Campos dos Goytacazes, RJ: WTC, 2004.
Silveira, P. M.; Stone, L. F. Sistemas de preparo do solo e rotação de culturas na produtividade de milho, soja e trigo. Revista Brasileira de Engenharia Agrícola e Ambiental, 7(2), 240-244, 2003. Disponível em: <www.scielo.br/pdf/ rbeaa/v7n2/v7n2a09.pdf>

Souza, T. N.; Terra, R. P.; Oliveira, V. de P. S. de. Implantação do Complexo Portuário do Açu e atividades de pesca artesanal marinha do Norte Fluminense: um conflito socioambiental. Boletim do Observatório Ambiental Alberto Ribeiro Lamego, 3(2), 23-30, 2009. Disponível em: <http:// www.essentiaeditora.iff.edu.br/index.php/boletim/article/ view/2177-4560.20090010/492>

Souza, T. N.; Oliveira, V. de P. S. de. Conflito socioambiental entre atividades de pesca artesanal marinha e implantação de atividades portuárias no Norte Fluminense. Boletim do Observatório Ambiental Alberto Ribeiro Lamego, 4(2), 219-230, 2010. Disponível em: <http://www.essentiaeditora.iff.edu.br/index.php/boletim/article/view/21774560.20100021>

Vengosh, A.; Gieskes, J.; Mahn, C. New evidence for the origin of hypersaline pore fluids in the Mediterranean basin. Chemical Geology, 163(1), 287-298, 2000.

Veronezzi, F.; Fajardo, S. A paisagem na análise geográfica: considerações sobre uma paisagem rural em Guarapuava-PR. Revista GEOgraphia, 17(34), 204-220, 2015. Disponível em: < www.uff.br/geographia/ojs/index.php/ geographia/article/download/497/570>

Zanotti, R. F. Métodos multivariados aplicados ao melhoramento genético do feijoeiro visando ao aumento da tolerância ao estresse osmótico e biofortificação de grãos. Tese (Doutorado) - Programa de Pós-Graduação em Produção Vegetal. Universidade Federal do Espírito Santo, Alegre, 2015.

Zappes, C. A.; Oliveira, P. da C.; Di Benedito, A. P. M. Percepção de pescadores do norte fluminense sobre a viabilidade da pesca artesanal com a implantação de megaempreendimento portuário. Boletim do Instituto de Pesca, 42(1), 73-88, 2016. 